\title{
Socio-demographic profile of tobacco consuming students in age group of 15 to 25 years in Jammu region
}

\author{
Neha Choudhary ${ }^{1}$, Rakesh Bahl ${ }^{2 *}$ \\ ${ }^{\mathbf{1}}$ Demonstrator, ${ }^{2}$ Associate Professor, ${ }^{\mathbf{1 - 2}}$ Department of Community Medicine, GMC Jammu, Jammu \& Kashmir, India
}

*Corresponding Author: Rakesh Bahl

Email: rbrakeshbahl@gmail.com

\begin{abstract}
Introduction: Consumption of tobacco leads to a myriad of ill effects among the smokers as well as those in their proximity. This study was conducted in the population in the age group of 15-24 years, the vulnerable period of life when most of health-related behaviours develop.

Materials and Methods: 1.Study design: Cross- sectional study. 2. Participants: 300 students; 75 each from Schools, degree colleges, professional colleges and post graduate departments of University of Jammu, in the age group of 15 - 24 years belonging to different regions of Jammu, Kashmir and Ladakh. 3. Sampling: Stratified Systemic Sampling technique. 4. Study instrument: A subset of key questions from Global Adult Tobacco Survey (GATS) $2^{\text {nd }}$ edition.

Results: Prevalence of smoking was $11.33 \%$. Non indulgence in smoking was seen among students aged below 16 years, and was seen to be twice among over 20 years (16.77\%) as compared to 17-19 years group (9.37\%). Among male students, it was ten- times (20.66\%) higher than females $(2 \%)$. It was higher in government than in private institutions $(13.33 \%$ vs. 9.33\%). Prevalence of smokeless tobacco consumption was $2 \% ; 3.35 \%$ in $\geq 20$ years age group, $1.04 \%$ among $17-19$ years and nil among $\leq 16$ year age. Male to female ratio was 5 to 1. Ratio of prevalence in Private institutions to government institutions was more than 3 to 1 .

Conclusion: There is an urgent need to curb the use of tobacco among the sub-groups of students with higher prevalence. This can be achieved by strengthening political and administrative will, implementing tobacco free school guidelines and establishing effective multisectoral coordination, as tobacco control is beyond the scope of health department.
\end{abstract}

Keywords: Framework Convention for Tobacco Control, Global Adult Tobacco Survey, Non Communicable Diseases.

\section{Introduction}

Tobacco remains the most important avoidable risk for the four classes of NCDs. It kills around 6 million people each year and more than 5 million of those deaths are the result of direct tobacco use while more than 6 lakh are the result of non-smokers being exposed to second-hand smoke. Nearly $80 \%$ of more than 1 billion smokers worldwide live in lowand middle-income countries. ${ }^{1}$ India is the second largest consumer of tobacco globally. ${ }^{2}$ It is estimated to cause about $71 \%$ of all lung cancer deaths, $42 \%$ of chronic respiratory disease and nearly $10 \%$ of cardiovascular disease. ${ }^{3}$ Tobacco-related cancers constitute roughly $40 \%$ of all male cancers in India. ${ }^{4}$ India has signed Framework Convention for Tobacco Control (FCTC) for halting tobacco consumption in the country. ${ }^{5}$

From Global Adult Tobacco Survey (GATS) $1^{6}(2009-$ 2010) to GATS 2 (2016- 2017), ${ }^{7}$ the prevalence of tobacco use has declined by $6 \%$. The number of tobacco users has declined by about 81 lakh. ${ }^{8}$ Due to the fact that tobacco smoking is regarded fashionable in most of the sections of the society, younger age group is more likely to inculcate this habit in comparison to the other age groups so as to boost their social acceptance and image. This behaviour is then carried forward in life and gets established and raises the likelihood of developing NCDs.

\section{Materials and Methods}

Study was conducted on students, in 15- 25 age group, from different regions of Jammu, Kashmir and Ladakh, and studying in various Schools, Colleges in Jammu city and Post Graduate (PG) departments of the University of Jammu. Each PG department of Jammu University (JU) was treated as one separate institution for the purpose of sampling._Permission from Institutional Ethics Committee GMC, Jammu (IECGJ) followed by Director Education and Heads of respective institutions was sought and the study was initiated. A sample of 300 students, 75 students each from Schools, Professional Colleges, Degree Colleges and Departments of JU was taken. Stratified Systemic Sampling technique was followed for the selection of the participants in the following fashion: 


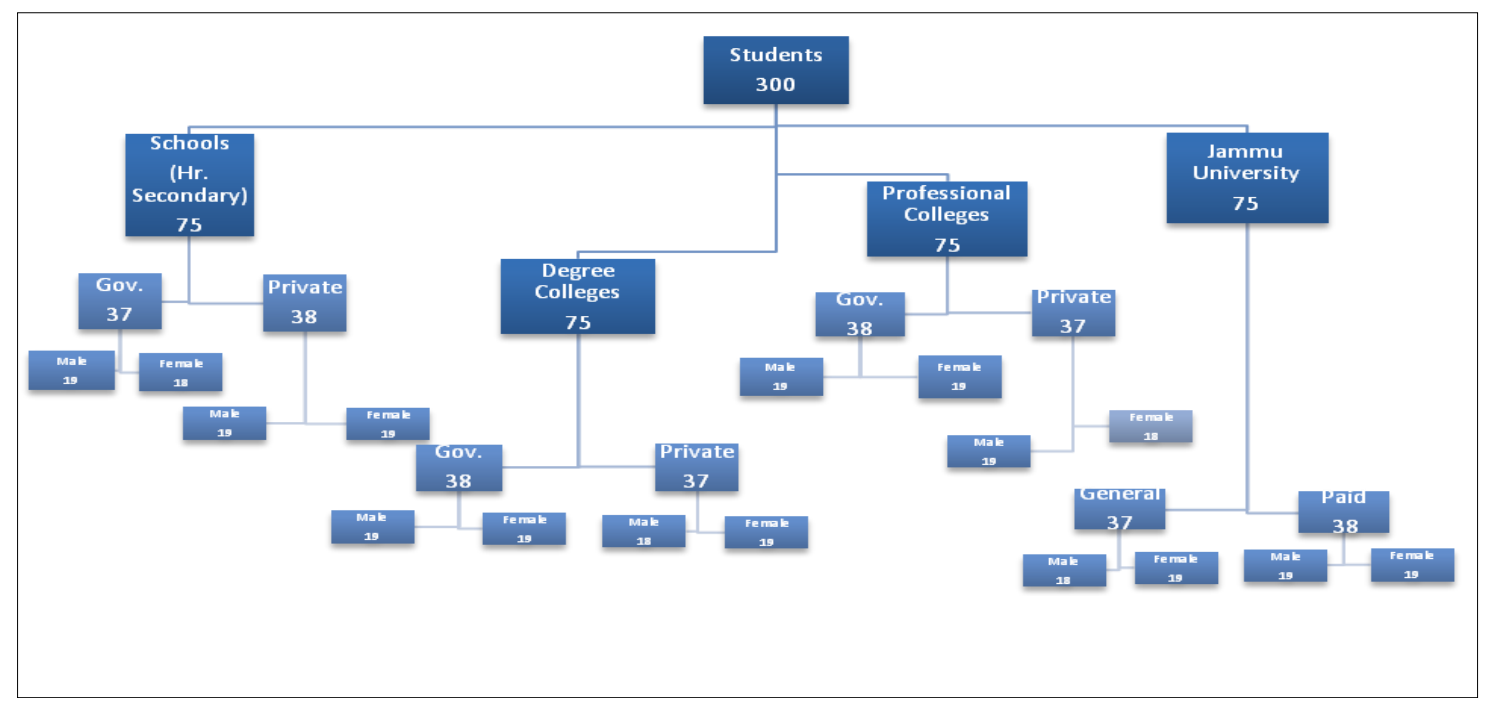

Fig. 1: Flow chart showing sample covered

37 \& 38 students from government and private schools respectively were taken. Similarly, $38 \& 37$ students from each of government and private Degree colleges and $38 \&$ 37 students from government and private Professional colleges were chosen. In the same manner, 37 \& 38 students pursuing PG in general \& private courses from different departments of JU were taken. Then each of 37 students were stratified into 19 males and 18 females. Similarly, each of 38 students were divided into 19 males and 19 females. This stratification was done so as to maintain a balance of equal males and females, i.e. 150 each. Also, this ensured an equal participation of students from government and private setup (again, 150 each). The institutions were selected by draw of lot method.

A map of the area falling under Jammu Municipal Corporation (JMC) was obtained from JMC office. The institutions were selected by the draw of lot method. After selection of the institutions and departments, the respective Heads of institutions were explained about the purpose and procedure of the study. Consent was obtained from those agreeing to participate in the study. Various streams, classes and courses in the schools, colleges and JU were selected as per recommendations by their Heads. Students were selected from attendance register by simple random sampling technique involving draw of lots, separate for boys and girls. Each of the students selected was met in person and their consent for participation was taken. For minor students, the assent of their parents/ guardians was obtained. In case of refusals or absence, a new lot was drawn.

Consumption of Tobacco was assessed using Tobacco question from surveys, a subset of key questions from Global Adult Tobacco Survey (GATS) $2^{\text {nd }}$ Edition. ${ }^{9}$ For the purpose of computing results, tobacco smoking was categorized under smokers and ex- smokers as well as consumers (current + past), current and past consumers of smokeless tobacco were clubbed together as 'consumers'.
Exposure to smoke at home and indoor areas of work have been put under exposed category of passive smoking.

Each student was interviewed in person. Face to face interview sessions were conducted after assuring confidentiality and rapport building. Average time was around 20-30 minutes per student. Data was analyzed in terms of numbers and proportions.

\section{Results}

Table 1 indicates that nearly half $(49.66 \%)$ of the students in our study were over 20 years of age, followed by $32 \%$ in the 17-19 year age group and $\leq 16$ year group comprising $18.33 \%$ of students . Also, majority of students (82.33\%), belonged to Hindu community and $78 \%$ hailed from nuclear families (Fig.2).

Table 2 reveals that in both govt. \& private institutions and among male and female groups, only $29 \%$ student's fathers were graduates. In comparison to private institutions $(0.66 \%)$, a higher percentage of fathers of the students in govt. institutions $(4 \%)$ were illiterate. $95 \%$ of fathers and $25 \%$ of the mothers of students belonged to the working class. Over all the prevalence of smoking was found to be $11.33 \%$.

Table 3 shows there was no indulgence in smoking seen among students in the age group $\leq 16$ years, and was nearly twice as high in $\geq 20$ years $(16.77 \%)$ as compared to $17-19$ years group $(9.37 \%)$. Number of male smokers $(20.66 \%)$ was ten times higher than female smokers $(2 \%)$ and it was more frequent in govt. (13.33\%) than in private institutions $(9.33 \%)$. Also, all the female smokers belonged to private institutions only (Fig. 3). 13.66\% student used to smoke in the past. Number of male students $(22.66 \%)$ was 5 times higher than their female counterparts $(4.66 \%)$, percentage of past smokers was more in private (16\%) as compared to the govt. institutions $(11.33 \%)$. Percentage of ex- smokers over 20 years of age $(20.13 \%)$ was nearly twice as that in $17-19$ year age group $(10.41 \%)$. 
In Table 4, Male students $(60 \%)$ were exposed much higher than their female counterparts $(42 \%)$ and exposure was higher among those in govt. (53.33\%) than in private institutions $(48.66 \%)$. Also, among male students, the ones in govt. institutions were exposed slightly more than those in private institutions.

Table 5 reveals $2 \%$ of the students consumed smokeless tobacco and its consumption was highest in $\geq 20$ years age group $(3.35 \%)$ which was nearly three times as that in 17-19 years $(1.04 \%)$ and nil in $\leq 16$ year age group.

It was seen that, consumption was about five times higher among male students (3.33\%) in comparison to their female counterparts $(0.66 \%)$ and more among students studying in private $(5.33 \%)$ than in govt. institutions $(1.33 \%)$.

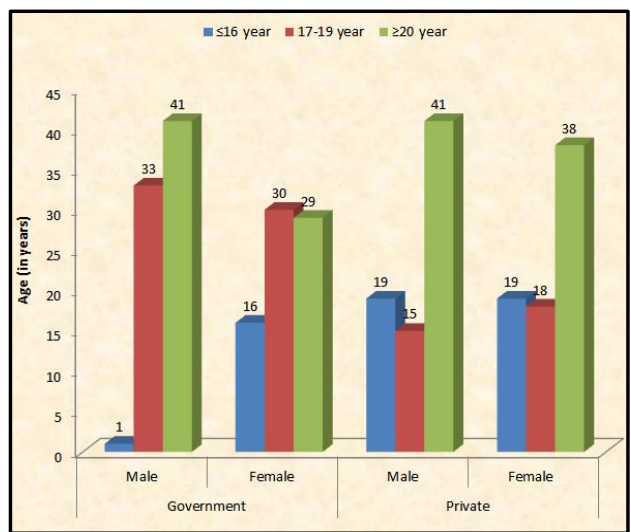

Fig. 2: Age and gender wise distribution of students

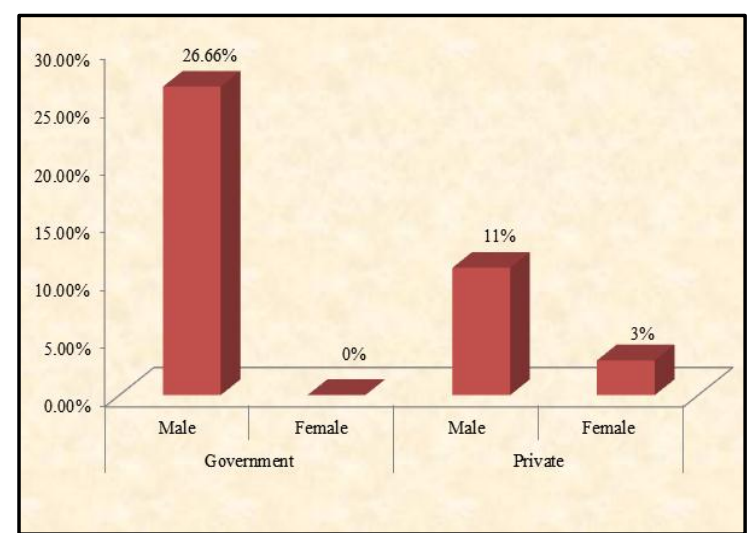

Fig. 3: Institution and gender wise distribution of students based on smoking

Table 1: Distribution of students as per Age, Gender and Socio- demographic characteristics

\begin{tabular}{|c|c|c|c|c|c|}
\hline \multirow{2}{*}{ Age group (in years) } & \multicolumn{2}{|c|}{ Government n=150 } & \multirow{2}{*}{ Potal n (\%) } \\
\cline { 2 - 5 } & Male n (\%) & Female n (\%) & Male n (\%) & Female n (\%) & \\
\hline$\leq 16$ & $1(1.33)$ & $16(21.33)$ & $19(25.33)$ & $19(25.33)$ & $55(18.33)$ \\
\hline $17-19$ & $33(44)$ & $30(40)$ & $15(20)$ & $18(24)$ & $96(32)$ \\
\hline$\geq 20$ & $41(54.66)$ & $29(38.66)$ & $41(54.66)$ & $38(50.66)$ & $149(49.66)$ \\
\hline Total & $75(50)$ & $75(50)$ & $75(50)$ & $75(50)$ & 300 \\
\hline \multicolumn{7}{|c|}{ Socio-demographic Parameters } \\
\hline \multicolumn{7}{|c|}{ Religion } \\
\hline Hindu & $64(85.33)$ & $63(84)$ & $63(84)$ & $57(76)$ & $247(82.33)$ \\
\hline Muslim & $6(8)$ & $7(9.33)$ & $8(10.66)$ & $12(16)$ & $33(11)$ \\
\hline Christian & $0(0)$ & $0(0)$ & $1(1.33)$ & $0(0)$ & $1(0.33)$ \\
\hline Sikh & $5(6.66)$ & $3(4)$ & $3(4)$ & $5(6.66)$ & $16(5.33)$ \\
\hline Others & $0(0)$ & $2(2.66)$ & $0(0)$ & $1(1.33)$ & $3(1)$ \\
\hline Total & $75(50)$ & $75(50)$ & $75(50)$ & $75(50)$ & 300 \\
\hline \multicolumn{7}{|c|}{ Type of Family } & $15(20)$ & $21(28)$ & $18(24)$ & $66(22)$ \\
\hline Joint & $12(16)$ & $60(80)$ & $54(72)$ & $57(76)$ & $234(78)$ \\
\hline Nuclear & $63(84)$ & $75(50)$ & $75(50)$ & $75(50)$ & 300 \\
\hline Total & $75(50)$ &
\end{tabular}


Table 2: Distribution of students as per education and occupation status of Father and Mother

\begin{tabular}{|c|c|c|c|c|c|}
\hline \multirow[t]{2}{*}{ Father } & \multicolumn{2}{|c|}{ Government $n=150$} & \multicolumn{2}{|c|}{ Private $n=150$} & \multirow[t]{2}{*}{ Total n (\%) } \\
\hline & Male n (\%) & Female n (\%) & Male n (\%) & Female n (\%) & \\
\hline $\begin{array}{l}\text { a) Education } \\
\text { Illiterate }\end{array}$ & $2(2.66)$ & $4(5.33)$ & $1(1.33)$ & $0(0)$ & $7(2.33)$ \\
\hline Graduate & $18(24)$ & $22(29.33)$ & $20(26.66)$ & $28(37.33)$ & $88(29.33)$ \\
\hline Postgraduate & $9(12)$ & $1(1.33)$ & $7(9.33)$ & $10(13.33)$ & $27(9)$ \\
\hline Professional & $7(9.33)$ & $11(14.66)$ & $7(9.33)$ & $16(21.3)$ & $41(13.66)$ \\
\hline Total & $75(50)$ & $75(50)$ & $75(50)$ & $75(50)$ & 300 \\
\hline $\begin{array}{l}\text { b)Occupation } \\
\text { Working }\end{array}$ & $68(90.66)$ & $71(94.66)$ & $72(96)$ & $74(98.66)$ & $285(95)$ \\
\hline Non working & $7(9.33)$ & $4(5.33)$ & $3(4)$ & $1(1.33)$ & $15(5)$ \\
\hline Total & $75(50)$ & $75(50)$ & $75(50)$ & $75(50)$ & 300 \\
\hline \multicolumn{6}{|c|}{ Mother } \\
\hline $\begin{array}{l}\text { a)Education } \\
\text { Illiterate }\end{array}$ & $9(12)$ & $7(9.33)$ & $4(5.33)$ & $0(0)$ & $20(6.66)$ \\
\hline Graduate & $11(14.66)$ & $4(5.33)$ & $4(5.33)$ & $15(20)$ & $34(11.33)$ \\
\hline Postgraduate & $1(1.33)$ & $5(6.66)$ & $3(4)$ & $5(6.66)$ & $14(4.66)$ \\
\hline Professional & $8(10.66)$ & $5(6.66)$ & $1(1.33)$ & $0(0)$ & $14(4.66)$ \\
\hline Total & $75(50)$ & $75(50)$ & $75(50)$ & $75(50)$ & 300 \\
\hline $\begin{array}{l}\text { b)Occupation } \\
\text { Working }\end{array}$ & $20(26.66)$ & $29(28.66)$ & $15(20)$ & $22(29.33)$ & $86(28.6)$ \\
\hline Non working & $55(73.33)$ & $46(61.33)$ & $60(80)$ & $53(70.66)$ & $214(71.33)$ \\
\hline Total & $75(50)$ & $75(50)$ & $75(50)$ & $75(50)$ & 300 \\
\hline
\end{tabular}

Table 3: Distribution of students as per Active smoking status (tobacco)

\begin{tabular}{|c|l|c|c|c|c|}
\hline Age group (in years) & \multirow{2}{*}{ Category } & \multicolumn{2}{|c|}{ Government n=150 } & \multicolumn{2}{c|}{ Private n=150 } \\
\cline { 2 - 6 } & & Male & Female & $0 / 19$ & $0 / 19$ \\
\hline$\leq 16$ & Smokers & $0 / 1$ & $0 / 16$ & $0 / 19$ & $0 / 19$ \\
\cline { 2 - 6 }$(55)$ & Ex- smokers & $1 / 1$ & $0 / 16$ & $0 / 15$ & $2 / 18$ \\
\hline $17-19$ & Smokers & $7 / 33$ & $0 / 30$ & $2 / 15$ & $3 / 18$ \\
\cline { 2 - 6 }$(96)$ & Ex- smokers & $2 / 33$ & $3 / 30$ & $11 / 41$ & $1 / 38$ \\
\hline$\geq 20$ & Smokers & $13 / 41$ & $0 / 29$ & $19 / 41$ & $0 / 38$ \\
\cline { 2 - 6 }$(149)$ & Ex- smokers & $10 / 41$ & $1 / 29$ & $32 / 75$ & $6 / 75$ \\
\hline
\end{tabular}

Table 4: Distribution of passive smoking among students

\begin{tabular}{|l|c|c|c|c|c|}
\hline Exposed to passive smoking & Age group (in years) & \multicolumn{2}{|c|}{ Government $\mathbf{n = 1 5 0}$} & \multicolumn{2}{|c|}{ Private n=150 } \\
\cline { 3 - 6 } & & Male & Female & Male & Female \\
\cline { 2 - 6 } & $\leq 16(55)$ & $1 / 1$ & $9 / 16$ & $19 / 19$ & $13 / 19$ \\
\cline { 2 - 6 } & $17-19(96)$ & $27 / 33$ & $9 / 30$ & $6 / 15$ & $6 / 18$ \\
\cline { 2 - 6 } & $\geq 20(149)$ & $20 / 41$ & $14 / 29$ & $17 / 41$ & $12 / 38$ \\
\cline { 2 - 6 } & Total & $48 / 75$ & $32 / 75$ & $42 / 75$ & $31 / 75$ \\
\cline { 2 - 6 } & \multicolumn{5}{|l}{ Grand Total $(80+73)=153(51)$ Students } \\
\cline { 2 - 6 } & &
\end{tabular}

Table 5: Distribution of consumption status of smokeless tobacco among students

\begin{tabular}{|c|c|c|c|c|c|}
\hline Ever- Consumers & Age group (in years) & \multicolumn{2}{|c|}{ Government $\mathbf{n = 1 5 0}$} & \multicolumn{2}{c|}{ Private n=150 } \\
\cline { 2 - 6 } & & Male & Female & Male & Female \\
\cline { 2 - 6 } & $\leq 16(55)$ & $0 / 1$ & $0 / 16$ & $0 / 19$ & $0 / 19$ \\
\cline { 2 - 6 } & $17-19(96)$ & $0 / 33$ & $1 / 30$ & $0 / 15$ & $0 / 18$ \\
\cline { 2 - 6 } & $\geq 20(149)$ & $1 / 41$ & $0 / 29$ & $4 / 41$ & $0 / 38$ \\
\cline { 2 - 6 } & Total & $1 / 75$ & $1 / 75$ & $4 / 75$ & $0 / 75$ \\
\hline Grand Total (2+4) $=6$ (300) Students
\end{tabular}




\section{Discussion}

Despite the enormous lifestyle changes, experienced by our society in recent decades, there are only a few researches that have been carried out to study tobacco consumption among students in the age group of 15-25 years, a vulnerable period of life when health-related behaviours that drive the major chronic degenerative diseases, start or are reinforced.

Prevalence of smoking in our study was $11.33 \%$, which is in line with Global Adult Tobacco Survey (GATS 2) India, 2016-17 ${ }^{10}$ and others. ${ }^{11}$ Wide variation of tobacco consumption among different age groups can be attributed to the fact that lower age individuals are yet under parental control and also stringent laws do not permit them to buy and smoke tobacco and its products. Whereas, rise in number with advancing age might be explained by the craze of experimenting/ of fashion that usually begins in college life and so the negative behaviour persists all along; peer pressure by friends, economic independence, lack of fear of parents might also be the factors involved. Ten- times higher prevalence seen among male students $(20.66 \%)$ as compared to female students $(2 \%)$ is in line with other studies. ${ }^{12,13}$ This can be explained by the fact that males are introduced to cigarettes and other products much earlier in age by their families. Tobacco, if used by parents or elder siblings, increases the children's likelihood of smoking. Smoking is seen to be slightly more frequent in government than in private institutions (13.33\% vs. $9.33 \%$ ), which might be explained due to lack of awareness on the part of parents and the environment under which students live. Prevalence of using smokeless tobacco in our study was $2 \%$.Similar trend of consumption of smokeless tobacco was seen i.e. highest among students over 20 years and nil in $\leq 16$ year age group. Five times higher prevalence among males than female students is consistent with other studies. ${ }^{12,13}$ Higher prevalence among students in private institutions can be due to the higher purchasing power among the former group. Higher prevalence of ex- smokers in private as compared to the govt. institutions points towards more awareness regarding ill effects of tobacco in the former group. Exposure to second- hand smoke was pervasive in all age groups and most of the students had an exposure to smoke at their homes only, signifying that this not only increases their likelihood to develop ill health but indulgence in smoking also. Higher exposure of male students might be due to comfort levels that exist between the same gender, and a higher exposure among students in govt. institutions points towards the lack of awareness about the hazards of passive smoking amongst their family members. This is also backed by the finding that among male students, the ones in govt. institutions were exposed slightly more than those in private institutions.

\section{Conclusion}

Our results should be considered a first step into the development of tailored and effective intervention programmes aiming to curb Tobacco consumption, a behaviour risk factor, among students at an early age so that it is not carried forward and sustained throughout life.

Strengths- Students were spread across different institutions making it a wider study as it takes transition period from school to college and to university into consideration; Stratified Sampling technique applied at every step rules out the probability of selection bias; Equal division of malefemale and students in government and private institutions (150 each) gives an equal sense of comparability.

Study has certain limitations that the results obtained should be cautiously generalised for the whole population as the sample size is small, it gives a snapshot of the problem in only one point in time as the design is cross sectional, underreporting of smoking can't be ruled out as students (esp. females) might not have admitted to the consumption of tobacco due to its social unacceptability.

\section{Acknowledgment}

We sincerely thank all the participants in the study for their cooperation.

\section{Source of Funding: None.}

\section{Conflict of Interest: None.}

\section{References}

1. World Health Organization. Tobacco [Internet]. 2016. [Updated 2016 June; cited 2016 Oct 25]. Available from:http://www.who.int/mediacentre/factsheets/fs339/en/.

2. Mishra GA, Pimple SA, Shastri SS. An overview of the tobacco problem in India. Indian J Med Paediatr Onco.2012;33(3):139-45. DOI:10.4103/0971-5851.103139.

3. World Health Organization. Global Status Report on Non Communicable Diseases 2010. Description of the global burden of NCDs, their risk factors and determinants [Internet]. Chapter 1, Burden: mortality, morbidity and risk factors [cited 2016 Oct 25]. Available from:

http://www.who.int/nmh/publications/ncd_report_chapter1.pdf ?ua $=1$.

4. Gandhi AK et al. Burden of preventable cancers in India: Time to strike the cancer epidemic. J Egyptian Nat Cancer Inst 2016. Available from: http://dx.doi.org/10.1016/j.jnci.2016.08.002.

5. United Nations Treaty Collection. Chapter IX, 4.WHO Framework Convention on Tobacco Control, Geneva. 2003, May;166. Available from: https://treaties.un.org/pages/ViewDetails.aspx?src=TREATY\& mtdsg_no $=I X-4 \&$ chapter $=9 \&$ clang $=\_$en .

6. GlobalAdultTobaccoSurvey.IndiaFactsheet200910.Availablefr om:https://www.who.int/tobacco/surveillance/en_tfi_india_gat s_fact_sheet.pdf.

7. Global Adult Tobacco Survey. India Fact sheet 2016-17. Available from: https://www.mohfw.gov.in/sites/default/files/GATS$2 \% 20$ FactSheet.pdf. 
8. World Health Organisation. Ministry of Health and Family Welfare, Government of India. Global Adult Tobacco Survey GATS2 India (2016-2017).

9. WHO. Global Tobacco Surveillance System (GTSS). Tobacco questions for Surveys. A subset of key questions from Global Adult Tobacco Survey (GATS) $2^{\text {nd }}$ edition. Available from:http://www.who.int/tobacco/surveillance/en_tfi_tqs.pdf.

10. Global adult tobacco survey report.

11. Aryal k.k. The Burden and Determinants of Non Communicable Diseases Risk Factors in Nepal: Findings from a Nationwide STEPS Survey PLOS ONE | DOI:10.1371/journal.pone.0134834.

12. A. Krishnan. Prevalence of Risk Factors for NonCommunicable Disease in a Rural Area of Faridabad District of Haryana. Indian J Public Health.2008:52(3).

13. Akansha Singh, Laishram Ladusingh. Prevalence and Determinants of Tobacco Use in India: Evidence from Recent Global Adult Tobacco Survey Data. PLOS ONE DOI:10.1371/journal.pone.0114073 December 4, 2014.

How to cite this article: Choudhary N, Bahl R. Sociodemographic profile of tobacco consuming students in age group of 15 to 25 years in Jammu region. Int $J$ Forensic Community Med.2019;6(4):214-219. 